\title{
Entrapment of the Temporal Horn: A Form of Focal Non-communicating Hydrocephalus Caused by Intraventricular Block of Cerebrospinal Fluid Flow \\ -Report of Two Cases-
}

\author{
Ryuichi Tsugane, Masami SHImoda, Tsutomu YAMAgUCHI, \\ Isao YAMAMOTO and Osamu SATO
}

Department of Neurosurgery, Tokai University School of Medicine, Isehara, Kanagawa

\begin{abstract}
In two cases of entrapment of the temporal horn, computed tomography demonstrated the typical appearance of a comma-shaped homogeneous area isodense with water surrounded by a periventricular low-density area. The cause was probably choroid plexitis resulting in obstruction of the cerebrospinal fluid pathway at the atrium. External drainage followed by shunt emplacement is indicated.
\end{abstract}

Key words: hydrocephalus, meningitis, periventricular low density, temporal horn

\section{Introduction}

Focal ventricular dilatation of the temporal horn caused by an occlusion of the cerebrospinal fluid (CSF) pathway at the atrium of the lateral ventricle is a form of non-communicating hydrocephalus termed entrapment of the temporal horn. Infection of the choroid plexus and ventriculitis are the main pathogenetic processes at the atrium of the lateral ventricle. This condition has previously been little discussed.

Here, we report two patients with focal dilatation of the temporal horn with choroid plexitis and ventriculitis. Problems of diagnosis, pathogenesis, and treatment are discussed.

\section{Case Reports}

Case 1: A 34-year-old male was healthy until he developed headache and fever in April, 1981. Tuberculous meningitis was suspected after a lumbar CSF examination. Despite medical therapy for tuberculous meningitis, consciousness disturbance developed in July, 1981, and he was referred to our department.

On admission, he was somnolent and disoriented.
He had bilateral papilledema with retinal hemorrhage, left homonymous hemianopsia, and nuchal stiffness. Laboratory examinations showed 6800/ $\mathrm{mm}^{3}$ white blood cell (WBC) count, $10 \mathrm{~mm}$ blood sedimentation rate in the first hour, and $\mathrm{C}$-reactive protein (CRP) $(+)$. Table 1 shows the results of the lumbar CSF examination. Computed tomographic (CT) scans revealed focal dilatation of the right temporal horn with an extensive periventricular hypodensity area (Fig. 1A-C). Right transbrachial angiograms demonstrated a right temporal mass lesion without obvious abnormal staining. In the venous phase, the draining veins from the right temporal lobe were not well visualized.

Table 1 CSF examinations in our cases

\begin{tabular}{|c|c|c|c|c|c|}
\hline & $\begin{array}{c}\text { Cell } \\
\text { count } \\
\left(/ \mathrm{mm}^{3}\right)\end{array}$ & $\begin{array}{l}\text { Polynuclear: } \\
\text { mononuclear }\end{array}$ & $\begin{array}{l}\text { Protein } \\
\text { (mg/dl) }\end{array}$ & $\begin{array}{c}\text { Sugar } \\
(\mathrm{mg} / \mathrm{dl})\end{array}$ & Culture \\
\hline \multicolumn{6}{|l|}{ Case 1: } \\
\hline Lumbar & 102 & $23: 79$ & 200 & 68 & - \\
\hline $\begin{array}{l}\text { Temporal } \\
\text { horn }\end{array}$ & 2 & $1: 1$ & 40 & 75 & - \\
\hline \multicolumn{6}{|l|}{ Case 2: } \\
\hline $\begin{array}{c}\text { Frontal } \\
\text { horn }\end{array}$ & 3 & $1: 2$ & 3200 & 78 & - \\
\hline $\begin{array}{l}\text { Temporal } \\
\text { horn }\end{array}$ & 5 & $1: 4$ & 20 & 85 & - \\
\hline
\end{tabular}


His condition progressively deteriorated. Left hemiparesis and stupor evolved. The diagnosis was entrapment of the temporal horn by an enhanced mass lesion in the atrium of the right lateral ventricle. The right temporal horn was decompressed by a CSF tap and a drainage tube was emplaced. Culture of CSF from the right temporal horn demonstrated no infectious organisms. Drainage was maintained for 7 days, collecting $400 \mathrm{ml}$ of clear CSF. His condition improved remarkably with clear consciousness and disappearance of hemiparesis. However, removal of the drainage tube was followed by deterioration of the consciousness. Consequently, a shunt tube from the right temporal horn to the peritoneal cavity was emplaced on August 19, 1981. Postoperatively, pleocytosis and increased protein content in the lumbar CSF persisted but the clinical signs improved. CT scans showed adequate decompression of the temporal horn and disappearance of the periventricular low-density area. The midline shift had disappeared (Fig. 1D-F).

He was discharged without neurological deficit and received oral isoniazid and refampicin. He was readmitted 40 days later with fever and nausea. Chronic meningitis with generalized hydrocephalus was found. His condition progressively worsened. Severe meningitis followed and eventually he died on December 7, 1981.

Autopsy demonstrated many foci of tuberculous infection in the lung and spleen, involving lymph nodes of the lung, trachea, neck, pancreas, and mesentery. Tuberculous meningitis was verified.
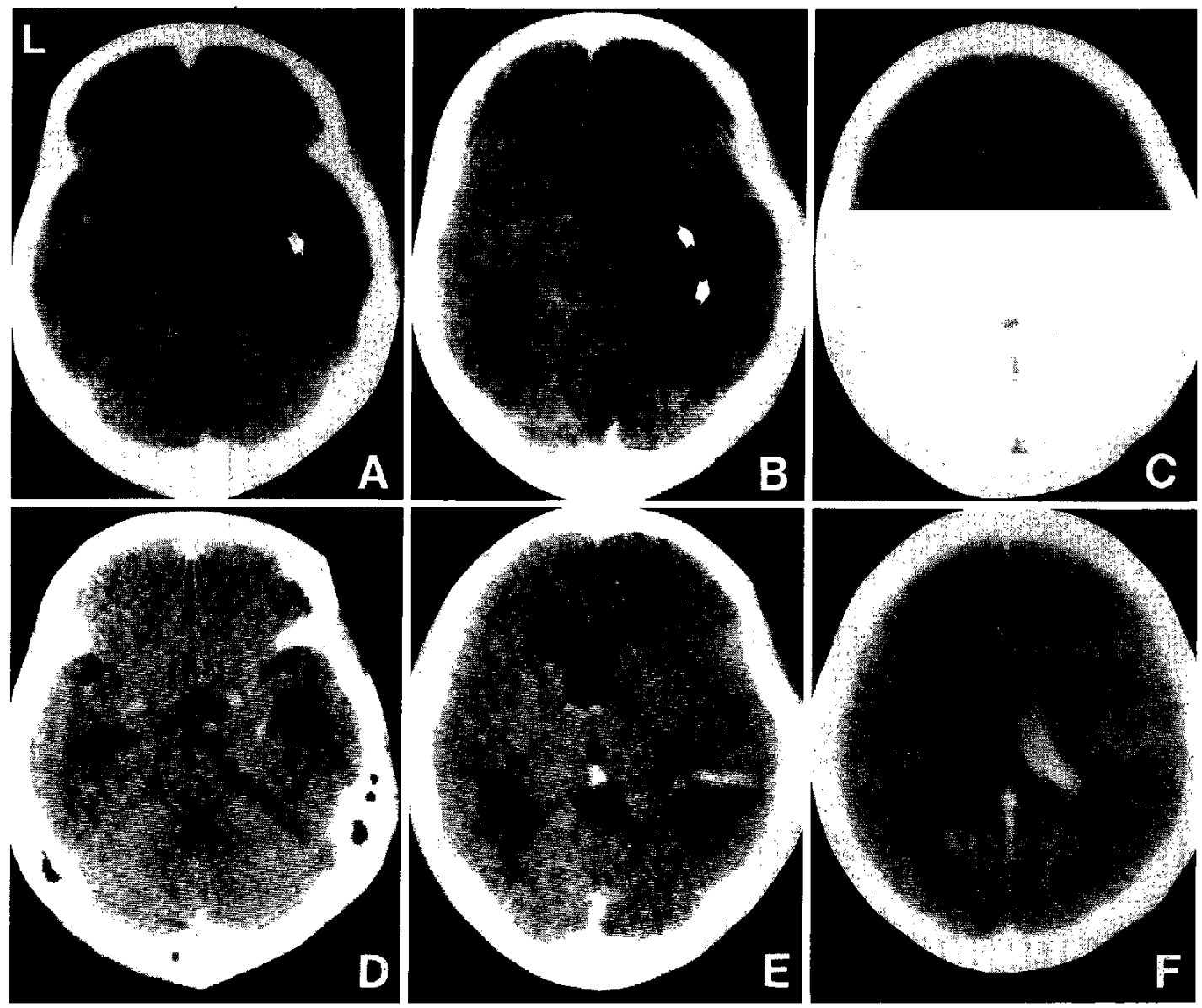

Fig. 1 Case 1. A-C: Preoperative postcontrast CT scans. Arrows in A, B show the lateral wall of the dilated temporal horn. Periventricular low-density area is evident in the white matter of the affected temporal lobe. The CT density is similar to the ventricular fluid. Midline shift is prominent. The choroid plexus is enhanced in the affected side. D-F: Postoperative postcontrast CT scans. The temporal horn is decompressed by a temporal horn-peritoneal shunt and the periventricular low-density area has almost disappeared. Enhancement of the choroid plexus is more prominent compared with preoperatively. 
The intraventricular mass lesion was a tuberculous infection of the choroid plexus with multiple small foci of caseation. The ventricular wall adhered to the hypertrophic choroid plexus at the junction of the atrium and the right lateral ventricle. The right temporal horn appeared slit-like. This autopsy was reported previously. ${ }^{14)}$

Case 2: A 44-year-old diabetic female noted paresis of the left lower extremity in January, 1988. Subsequently fever and headache developed, and she was admitted to Tokai University Hospital on February $10,1988$.

On admission, she was drowsy but arousable with left hemiparesis and nuchal stiffness. Blood examination found WBC count of $14,900 / \mathrm{mm}^{3}$, blood sedimentation rate of $48 \mathrm{~mm}$ in the first hour, CRP $3.8 \mathrm{mg} / \mathrm{dl}$, and fasting blood sugar level of $190 \mathrm{mg} /$ dl. CT scans revealed multiple, small ring-like enhancements in the white matter of the right cerebral hemisphere with massive edema. No hydrocephalus was present.

The diagnosis was multiple brain abscesses. CTguided aspiration of the abscess cavities was performed twice in the following month. A catheter was left in an abscess cavity near the right frontal horn. Culture of the abscess contents demonstrated $\alpha$ - and

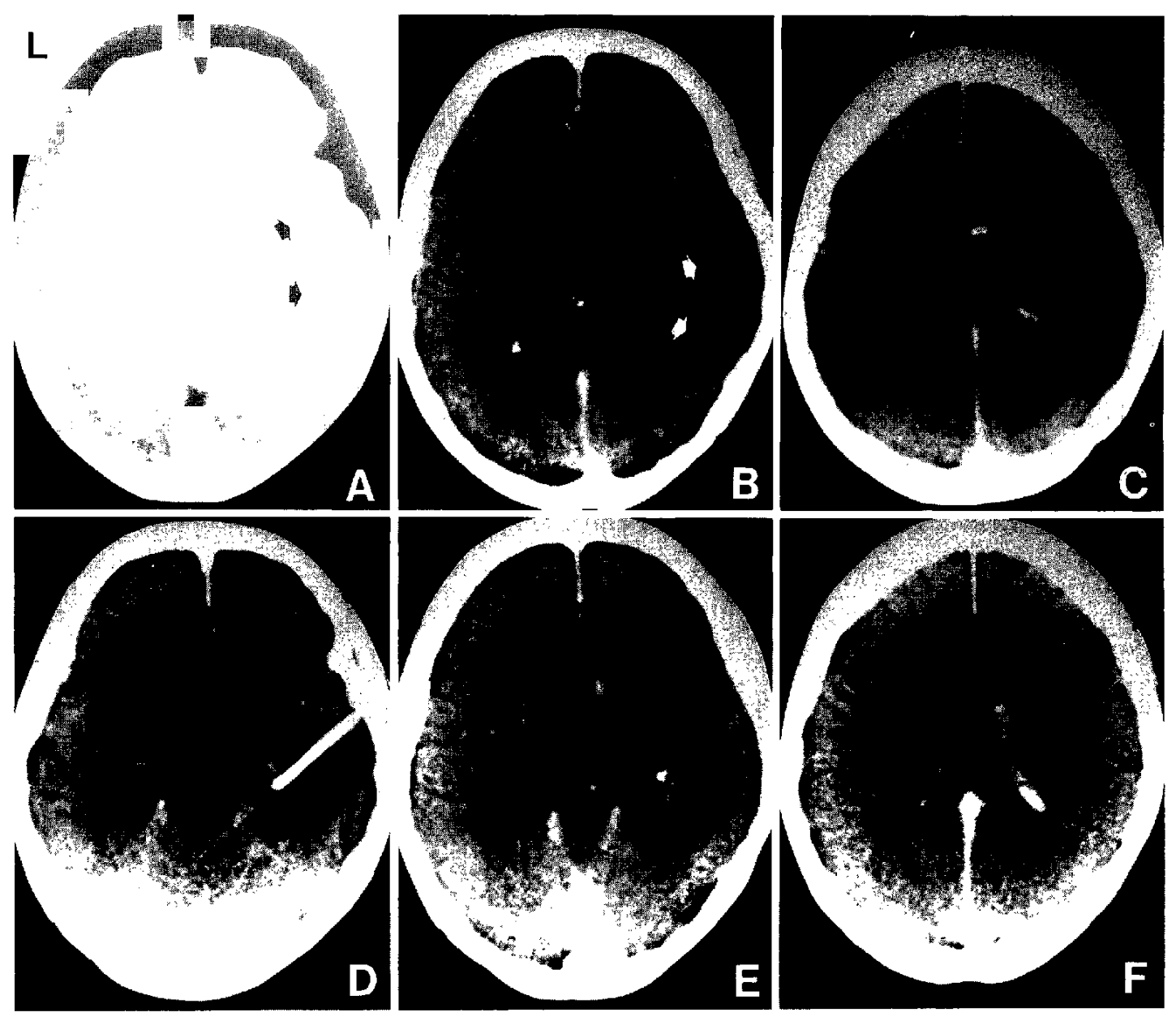

Fig. 2 Case 2. A-C: Preshunt postcontrast CT scans, showing dilated temporal horn with prominent periventricular low attenuation. Arrows in A, B show the lateral wall of the temporal horn. Low density is present in the periventricular area of the temporal horn and in the anterior half of the affected hemisphere $(C)$ which was suspected to be the perifocal edema of the brain abscess. The anterior horn is also dilated but the periventricular low-density area is minimal (B). The choroid plexus is enhanced on the affected side (B, C). D-F: Postshunt postcontrast CT scans. A shunt tube is inserted in the atrium (D) and the temporal horn is adequately drained. Periventricular low density has completely disappeared. The choroid plexus is still highly enhanced compared to the opposite side. The frontal horn is also collapsed (E). 
$\beta$-streptococci. Postoperatively, she remained drowsy. A small abscess near the right atrium spontaneously ruptured into the lateral ventricle. The ventricular CSF showed increased cell count. Her consciousness deteriorated to stupor with dense left hemiplegia. CT scans revealed dilated right frontal and temporal horns (Fig. 2A-C). On April 2, 1988, the frontal and temporal horns were drained simultaneously. Table 1 gives the results of CSF examination. Later, the temporal horn drainage was converted to a temporal horn-peritoneal shunt. The frontal horn tube was removed. Postoperative CT scans showed collapsed temporal horn and disappearance of the periventricular low-density area (Fig. 2D-F).

She recovered uneventfully after antibiotic therapy. She is now receiving insulin but is neurologically normal.

\section{Discussion}

The pathogenesis in our cases was occlusion of the CSF pathway at the atrium of the lateral ventricle based on examination of CSF specimens taken simultaneously from the temporal horn and from the other cavity of the CSF pathway. The temporal horn contains the choroid plexus where CSF is produced continuously, so focal obstructive hydrocephalus will result from the CSF production-absorption imbalance.

Table 2 summarizes the reported cases including ours. The main pathogenesis of obstruction in the atrium was the infection of the central nervous system. ${ }^{7,10,16)}$ Five cases had bacterial or cryptococcal meningitis including brain abscess. Postcontrast CT scans indicated choroid plexitis in two cases ${ }^{10,16)}$ and autopsy found choroid plexitis due to tuberculous in- fection causing obstruction of the CSF pathway in our Case 1. About half of tuberculous meningitis cases demonstrated choroid plexitis at autopsy. ${ }^{4)}$ Choroid plexitis and concomitant ventriculitis probably blocked the CSF flow at the junction of the atrium and the lateral ventricle. Other pathogeneses were recurrent glioma and postoperative scar formation after removal of arteriovenous malformation. ${ }^{7}$

Occlusion of the CSF pathway by a neoplasm or malformation is a well known cause of non-communicating hydrocephalus. The interventricular foramina, aqueduct, and fourth ventricular outlets are frequent sites of the lesion. Intraventricular occlusion of the CSF pathway in pediatric meningitis is called "compartmentalization," "6) "multiloculated hydrocephalus," ") or "intraventricular septation." "12)

Another possibility for the dilatation of the temporal horn is pseudoventricle or paraventricular cavitation. ${ }^{8,15,17)}$ Experimental ventriculitis using congenital hydrocephalic mice showed that subependymal cavitation eventually formed a large cavity. Such loculated portions of the ventricular system were never within the ventricular system but represented coalescence of paraventricular cysts into a pseudoventricle. This hypothesis has been applied to the mechanism of compartmentalization in pediatric ventriculitis. However, it is unclear whether the same mechanism occurs in adult ventriculitis. Our Case 1 autopsy gave no information since the dilated cavity was completely decompressed after the shunt operation.

Ordinary hydrocephalus causing symmetrical dilatation of the ventricular system and the temporal horn to the same extent as in our cases will not demonstrate periventricular low density on $\mathrm{CT}$ scans in the temporal horn. The CT densities in our cases were almost the same as the ventricular fluid. This

Table 2 Summary of reported cases

\begin{tabular}{|c|c|c|c|c|c|c|}
\hline Author (Year) & Age & Sex & Side & Cause & $\begin{array}{l}\text { Periventricular } \\
\text { low-density area }\end{array}$ & Treatment \\
\hline \multirow[t]{3}{*}{$\begin{array}{l}\text { Maurice-Williams and } \\
\text { Choksey }(1986)^{7)}\end{array}$} & 23 & $\mathbf{F}$ & rt & recurrent glioma & no scan & $\begin{array}{l}\text { direct communication } \\
\text { to the atrium }\end{array}$ \\
\hline & 35 & $\mathbf{F}$ & $\mathrm{rt}$ & tuberculous meningitis & yes & VA shunt \\
\hline & 30 & $\mathrm{~F}$ & lt & removal of AVM & yes & VP shunt \\
\hline $\begin{array}{l}\text { Ofori-Kwakye et al. } \\
(1986)^{10)}\end{array}$ & 35 & $\mathrm{~F}$ & $\mathrm{rt}$ & $\begin{array}{l}\text { cryptococcal } \\
\text { meningoencephalitis }\end{array}$ & yes & drainage \\
\hline $\begin{array}{l}\text { Yamamoto et al. } \\
(1987)^{16)}\end{array}$ & 2 & $\mathbf{F}$ & It & $\begin{array}{l}\text { streptococcal brain } \\
\text { abscess }\end{array}$ & yes & VP shunt \\
\hline Present Case 1 & 34 & $\mathbf{M}$ & $\mathrm{rt}$ & tuberculous meningitis & yes & drainage and VP shunt \\
\hline Present Case 2 & 44 & $\mathrm{~F}$ & rt & $\begin{array}{l}\alpha-\text { and } \beta \text {-streptococcal } \\
\text { brain abscess }\end{array}$ & yes & drainage and VP shunt \\
\hline
\end{tabular}

AVM: arteriovenous malformation, VA: ventriculoatrial, VP: ventriculoperitoneal. 
also occurred in the other reported cases. ${ }^{710,16)}$ The periventricular hypodensity area may be caused by transependymal CSF absorption or passive CSF diffusion through the disrupted ventricular wall, ${ }^{2,3,5,9,11)}$ resulting in migration of ventricular fluid into the brain parenchyma.

Excess extracellular brain fluid eventually drains into the venous system. Venous drainage from the affected temporal lobe has a significant influence on excess water retention in the periventricular area. In the temporal horn, the medial group of subependymal veins runs on the hippocampal surface and exits from the ventricle on the dentate gyrus. The inferior ventricular vein drains the superolateral wall of the temporal horn and exits through the choroidal fissure, where it joins the basal vein of Rosenthal. ${ }^{13)}$ Temporal horn dilatation and the resultant stretching of ventricular wall vessels will disturb the venous blood flow. A lesion in the atrium will further disturb venous drainage of CSF in the subependymal periventricular area.

CT demonstrates the dilated temporal horn as a comma-shaped homogeneous low-density area isodense with water. The periventricular low-density area was almost entirely in the temporal white matter and much less dense than the periventricular area in ordinary hydrocephalus. In these conditions, the mass effect is evident. Once the dilated temporal horn is identified on CT scans, entrapment of the temporal horn can be diagnosed without difficulty. If the temporal horn is not identified and the CT densities of the temporal horn and periventricular area are almost equal, the differential diagnosis includes temporal neoplasm, infection, and trauma. Therefore, good quality CT scans are required. Obviously, magnetic resonance imaging will provide further information.

Shunting of temporal ventricular fluid into another body cavity achieves good results. Suspected infection of the temporal horn indicates external drainage followed by shunt emplacement.

\section{References}

1) Albanese U, Tomasello F, Sampaola S, Picozzi P: Neuroradiological findings in multiloculated hydrocephalus. Acta Neurochir (Wien) 60: 297-311, 1982

2) Bering EA Jr, Sato O: Hydrocephalus: Changes in formation and absorption of cerebrospinal fluid within the cerebral ventricle. $J$ Neurosurg 20: 10501063,1963

3) Davson H, Hollingsworth G, Segal MB: The mechanism of drainage of the cerebrospinal fluid. Brain 93: 665-678, 1970

4) Greenfield G: Greenfield's Neuropathology, ed 2.
London, Edward Arnold, 1963, pp 151-153

5) Hiratsuka $H$, Tabata $H$, Tsuruoka $S$, Aoyagi $M$, Okada K, Inaba $\mathrm{Y}$ : Evaluation of periventricular hypodensity in experimental hydrocephalus by metrizamide CT ventriculography. $J$ Neurosurg 56: 235-240, 1982

6) Kalsbeck JE, Desousa AL, Kleimen MB: Compartmentalization of the cerebral ventricle as a sequela of neonatal meningitis. J Neurosurg 52: 547-552, 1980

7) Maurice-Williams RS, Choksey M: Entrapment of the temporal horn: A form of focal obstructive hydrocephalus. J Neurol Neurosurg Psychiatry 49: 238-242, 1986

8) McLone DG, Killion M, Yogev R, Sommers MW: Ventriculitis of mice and men, in American Society for Pediatric Neurosurgery (ed): Concepts in Pediatric Neurosurgery, II. Basel, Karger, 1982, pp $112-126$

9) Murata $T$, Handa $H$, Mori $K$, Nakano $Y$ : The significance of periventricular lucency on computed tomography: Experimental study with canine hydrocephalus. Neuroradiology 20: 221-227, 1981

10) Ofori-Kwakye SK, Wang AM, Morris JH, O'Reilly GV, Fisher EG, Rumbangh GL: Septation and focal dilatation of ventricles associated with cryptococcal meningoencephalitis. Surg Neurol 25: 253-260, 1986

11) Sahar A, Hochwald GM, Sadik AR, Ransohoff J: Cerebrospinal fluid absorption in animals with experimental obstructive hydrocephalus. Arch Neurol (Chicago) 21: 638-642, 1969

12) Schultz $P$, Leeds $N$ : Intra-ventricular septations complicating neonatal meningitis. $J$ Neurosurg 38: $620-$ 626, 1973

13) Stein R, Rosenbaum E: Intraventricular vein, in Newton T, Potts D (eds): Radiology of the Skull and Brain, vol 2, book 3. St Louis, Mosby, 1974, p 1922

14) Takizawa S, Kobatake K, Shinohara $Y$, Tsugane R: A case of tuberculous meningitis with prominent enhancement of choroid plexus on CT. Shinkei Naika 25: 123-129, 1986 (in Japanese)

15) Yamada H, Abe T, Tanabe $Y$ : Experimental and clinical studies on pathogenesis of intraventricular septations following meningo-ventriculitis in childhood. Monogr Neural Sci 8: 81-85, 1982

16) Yamamoto H, Matsukado $Y$, Nagahiro S: “Entrapment of the temporal horn" which developed during antibiotic therapy for multiple brain abscess. Shoni No Noshinkei 12: 415-421, 1987 (in Japanese)

17) Yamauchi Y, Kawamura Y, Matsumura H, McLone D: New concept of the pathogenesis of multiloculated ventricular system. Shoni No Noshinkei 9: 916, 1984 (in Japanese)

Address reprint requests to: R. Tsugane, M.D., Department of Neurosurgery, Tokai University School of Medicine, Boseidai, Isehara, Kanagawa 259-11, Japan. 